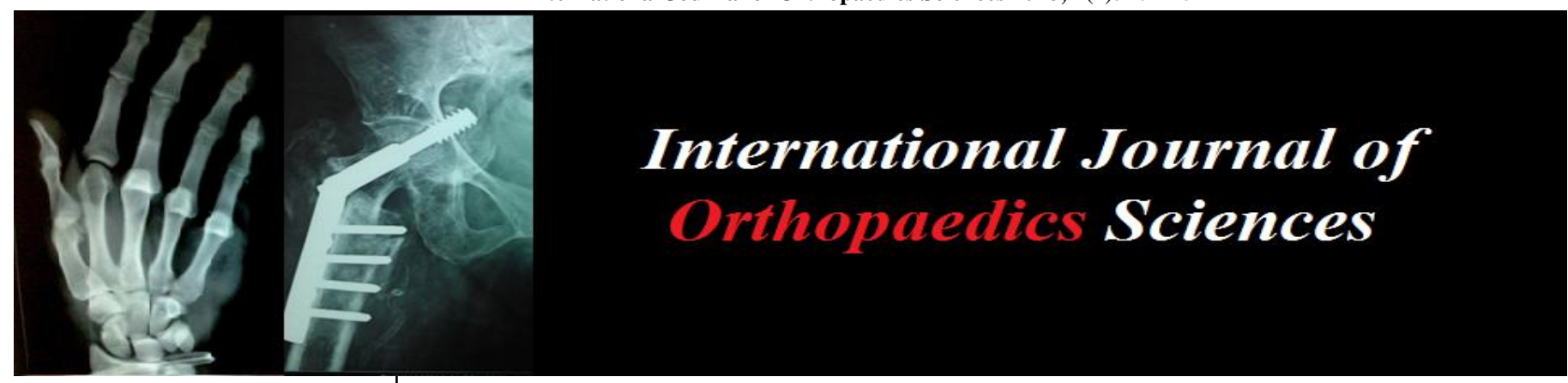

ISSN: $2395-1958$

IJOS 2018; 4(2): 151-154

(C) 2018 IJOS

www.orthopaper.com

Received: 04-02-2018

Accepted: 07-03-2018

Shrivastava Pradeep

MS (ortho), Specialist,

Department of orthopaedics,

Mahatma Gandhi Memorial

Medical College, Indore, Madhya

Pradesh, India

Jain saurabh

MS (ortho), Assistant Professor,

Department of orthopaedics,

Mahatma Gandhi Memorial

Medical College, Indore, Madhya

Pradesh, India

Gautam Vaibhav

MS (ortho), Resident,

Department of orthopaedics,

Mahatma Gandhi Memorial

Medical College, Indore, Madhya

Pradesh, India
Correspondence

Jain saurabh

MS (ortho), Assistant Professor,

Department of orthopaedics,

Mahatma Gandhi Memorial

Medical College, Indore, Madhya

Pradesh, India

\section{Outcome of radial nerve injury associated with fracture humeral shaft fractures treated with open reduction and internal fixation}

\author{
Shrivastava Pradeep, Jain saurabh and Gautam Vaibhav
}

DOI: https://doi.org/10.22271/ortho.2018.v4.i2c.22

Abstract

Radial nerve palsy with humeral shaft fracture is common injury which can result in significant motor and sensory impairment of the arm and the wrist, leading to a serious handicap. We attempted to find out the incidence of radial nerve palsy associated with humeral shaft fractures and its outcome after open reduction and internal fixation in 25 patients of complete primary radial nerve palsy in a total of 160 adult patients of with diaphyseal fracture of humerus with mean age of 33.2 years. The union was achieved in all 25 patients, at mean on 16.2 weeks with mean DASH score of 21.2 with $22(88 \%)$ patient had excellent to good outcome and only one patients had poor outcome and fair results in 2 patients. In all the patients except in one patient, the nerve recovered fully within 9 months with mean recovery time of 14.1 weeks (range 4 weeks to 7 months). To conclude, Radial nerve palsy is common with middle third oblique fractures of humeral shaft which is commonly neuropraxia with anatomical continuity which recovers completely in mean duration of four months without the need of any surgical repair.

Keywords: humeral shaft fracture, radial nerve injury

\section{Introduction}

A radial nerve injury is the most common peripheral nerve injury associated with humeral shaft fracture. It may be injured by the force that fractures the humeral shaft directly with contusion or laceration by a spur or by traction when the bone ends are forcibly separated either during initial trauma, closed reduction or during surgery ${ }^{[1,2]}$. It can result in significant motor and sensory impairment of the arm and the wrist, leading to a serious handicap.

This risk results due to the anatomic course of the radial nerve which during its course crosses back around the distal portion of the humeral shaft and is separated from it by a layer of triceps fibres and when the radial nerve pierces the lateral intermuscular septum to enter the anterior compartment of the arm, it is relatively more fixed in the distal arm as it penetrates the lateral intermuscular septum anteriorly and susceptible to injury ${ }^{[1,2]}$. As a rule, radial palsy regresses spontaneously, but in a few cases surgery may be required to achieve neurological recovery ${ }^{[3]}$. The management of radial nerve palsy associated with fractures of the shaft of the humerus is a controversial subject and poses a challenge to treating surgeon. Strong convictions for and against the either line of treatment conservative ${ }^{[4-7]}$ or operative ${ }^{[8-10]}$ can be drawn from the literature for these fracture shaft of humerus with radial nerve injury. Hence this study is attempted to find out the incidence of radial nerve palsy associated with humeral shaft fractures and to analyse outcome of radial nerve palsy after the treatment of fracture shaft of humerus with open reduction and internal fixation.

\section{Material and Methods}

This is a prospective study, which was conducted in the Department of Orthopaedics \& Traumatology, Mahatma Gandhi Memorial Medical College \& Maharaja Yashwantrao Hospital, Indore from November 2014 to November 2017. The study included 25 patients of complete primary radial nerve palsy in a total of 160 adult patients of with diaphyseal fracture of humerus. All diaphyseal fracture of the humerus either closed or open grade I with radial nerve palsy developing palsy due to trauma and before any treatment in a skeletally mature 
patients were included in the study. Humeral fracture with secondary radial nerve injury (radial nerve injury after treatment), skeletally immature patient, intra-articular fracture or pathological fractures were excluded from the study.

All patients with radial nerve palsy with fracture of the humerus were evaluated with detailed history with emphasis on mode of injury - high energy vs. low energy, time since injury, details of any treatment received - including manipulation and attempted reductions. Local and neurological (motor and sensory) examination was done and other associated injuries were ruled out. The muscles tested were brachioradialis (elbow flexion in mid-prone position), wrist extensors (extensor carpii radialis longus and brevis), thumb extensor and abductor and extensors of metacarpophalangeal joints. Sensory examination was done with emphasis on sensory loss over the dorsal aspect of forearm and dorsal surface of the first interosseous space that forms autonomous zone for the radial nerve. X-ray of arm anterio-posterior view and lateral views was done, in order to document level and type of fracture.

The fracture was managed initially by a $\mathrm{u}$ slab and then all patients were treated by open reduction and internal fixation with either LCP (locking compression plate) of DCP (dynamic compression plate), via posterior approach under brachial block or general anaesthesia. During the surgery exploration of radial nerve was done and the condition of nerve noted.

Post operatively, patients were immobilized for two weeks in arm pouch for fracture shaft of humerus and for wrist drop static cock-up splint was given for 6 weeks for radial nerve palsy. Suture removal was done at 2 weeks, following which all the patients were advice passive range of motion exercise. The patients were followed up at 1, 3, 6 and 12 months. At each follow up clinical sign of nerve recovery both sensory and motor were assessed. The results were assessed radiologically for union and functionally by DASH score (Diasability arm shoulder and hand).

\section{Results}

A total of 160 patients of fracture shaft of humerus were analysed in this study. Among these 160 patients 25 had primary radial nerve palsy immediate following trauma and were included in the study. The mean age of the patients was 33.2 years (range 19 years to 61 years). Out of 25 patients with radial nerve palsy $16(64 \%)$ were males and $9(36 \%)$ were females. There was no significant side predilection; right side was affected in 12 (48\%), whereas left side seen in $13(52 \%)$ patients. The most common mode of injury was fall (13 patients i.e 52\%) followed by road traffic accident (10 patients i.e $40 \%$ ), whereas one each was due to assault and sports injury. All of these injuries to the radial nerve were primary injuries sustained due to trauma only and none of the secondary radial nerve palsy was included in our series. Among these patients 16 patients $(64 \%)$ had fracture in the middle third of humerus, whereas $8(32 \%)$ patients at the lower third and one patient had upper third level of humerus fracture, thus more than $95 \%$ patients had fracture either in the middle or lower third of humerus. This radial nerve injury was associated with oblique fracture in $10(40 \%)$ patients, transverse in $10(40 \%)$ and $4(10 \%)$ patients each had spiral or communitted fracture.

On surgical treatment of fracture and nerve exploration, all the cases showed the nerve to be in anatomical continuity, although in $3(12 \%)$ and $2(8 \%)$ patients respectively, the nerve seemed severely contused and stretched. The union was achieved in all 25 patients, at mean on 16.2 weeks (range 13 week to 21 weeks). The mean DASH score of the series was 21.2 (range 9 to 76$)$ with $22(88 \%)$ patient had excellent to good outcome and only one patients had poor outcome and fair results in 2 patients.

In all the patients except in one patient, the nerve recovered fully within 9 months with mean recovery time of 14.1 weeks (range 4 weeks to 7 months). In one patient the nerve did not recovered at all and the patient underwent modified jones transfer after one year, after which she gained her wrist and finger extension. The relationship of the nerve recovery wasn't statistically insignificant with age group, sex, mode of injury, condition of nerve and fracture geometry whereas the recovery was statistically significantly associated with level of fracture suggesting faster recovery in upper third fracture with radial nerve palsy.

\section{Discussion}

The fracture shaft of humerus is a common injury and its association with radial nerve injury is also common. The incidence of the radial nerve palsy has been reported from $1.8 \%{ }^{23}$ to $35.3 \%$ in various studies ${ }^{[4-10]}$. In our series, radial nerve injury was seen in 25 patients out of 160 fracture shaft of humerus $(15.6 \%)$. The various electrodiagnostic studies are useful only after 3 to 6 weeks i.e. after the process of wallerian degeneration has set in, and by this time neurapraxic lesions would presumably have recovered. Moreover, electrodiagnostic studies are not able to distinguish between a severed nerve and unrecovered intact nerve and don't detect recovery much earlier than physical examination ${ }^{3}$. Hence eletrodiagnostic studies do not offer any predictability to the type of nerve injury in fracture shaft humerus.

Management of fracture shaft of humerus with radial nerve injury is a dilemma. The dilemma is whether the injured nerve is anatomically disrupted or continuous. Several authors have recommended early surgical exploration, as soon as radial nerve palsy is recognized ${ }^{[4-7]}$. Others have recommended observation and exploration of the injured nerve only if it fails to recover after an interval of 6 weeks to 6 months ${ }^{[8-10]}$.

Some studies have emphasized that the radial nerve palsy caused by a shaft fracture is a contusion and exploration of the nerve is unnecessary ${ }^{[4-10]}$. But since we treated all these patients of humeral shaft fracture with open reduction and internal fixation, we simultaneously explored the radial nerve to visualize and confirm the anatomic continuity of the nerve. In our series of 25 cases of radial nerve palsy with humeral shaft fractures, mean age was 33.2 years, male female ration was1.7, with fall or RTA as most common mode of injury, which was similar to the reported literature.

In our series, there was significant difference found in the radial nerve involvement with level of the fracture i.e. $4 \%$ in upper one third, $64 \%$ in middle one third, $32 \%$ in lower one third of humeral shaft. This is in concordance with the study of Garcia et al. ${ }^{[11]}$, Holstein ${ }^{[12]}$, Kettelkamp et al. ${ }^{[13]}$, Shaw et al. ${ }^{[14]}$, Packer et al. ${ }^{[15]}$, and Mast et al. ${ }^{[16]}$. Majority of cases of nerve palsies occurred in middle one third of the humerus shaft because radial nerve is in close contact with bone at the junction of upper $2 / 3^{\text {rd }}$ and lower $1 / 3^{\text {rd }}$ where radial nerve pierces the lateral intermuscular septum. Hence, it is easily damaged by decreased mobility of the nerve (table no. 1).

Fracture pattern was oblique in $40 \%$ cases, transverse in $32 \%$, spiral in $16 \%$ and comminuted in $12 \%$ of our series cases. This is in accordance with other series ${ }^{[11-21]}$. Comminution, signifying high energy absorption by the limb segment at the site of direct injury may result in direct radial nerve damage 
whereas the transverse fracture commonly angulated laterally may be responsible for indirectly damaging the radial nerve by either impingement by sharp fracture fragment or sudden stretching across the fracture site angulation.

In all our cases, nerve was found to be in anatomical continuity and hence no surgical repair was done as with other series ${ }^{[11-21]}$. The union in our series was achieved in all 25 patients, at mean on 16.2 weeks with mean DASH score of 21.2 and with $88 \%$ patient showing excellent to good outcome.

The reported rate of recovery of the radial nerve function shows variation from $100 \%$ to $64 \%$ with mean recovery time of 15 weeks in the series by Garcia et al. [11], Holstein [12], Kettelkamp et al. ${ }^{[13]}$, Shaw et al. ${ }^{[14]}$, Packer et al. ${ }^{[15]}$, and Mast et al. ${ }^{[16]}$. In our series, all patients except one recovered fully within 9 months with mean recovery time of 14.1 week). Recovery of nerve function did not correlated with age group, sex, geometry of fracture, condition of nerve, treatment of fracture and time of exploration of radial nerve. It only was related statically significant for level of fracture (chi square test, $\mathrm{x}^{2}=18.073$, $\mathrm{p}$ value $=.001$ ) only, which was due to thick muscle layer of triceps and relatively more mobility of the nerve in upper one third than middle and lower third.

To conclude, Radial nerve palsy is commonly seen in fractures of humerus specially involving the middle third of Humeral shaft, and highest in patients with oblique fracture. The nerve injury, commonly is neuropraxia with anatomical contunity which recovers completely in mean duration of four months without the need of any surgical repair. The outcome of radial nerve palsy was not found to be related to age group, sex, mechanism of injury, geometry of fracture, intraoperative condition of nerve except for the level of fracture. As complete recovery of the nerve can be quite delayed, patience is merited before considering tendon transfers.

Table 1: Results of various series

\begin{tabular}{|c|c|c|c|c|c|c|}
\hline Series & $\begin{array}{c}\text { No. of } \\
\text { fracture }\end{array}$ & $\begin{array}{c}\text { No. of lacerated } \\
\text { nerve }\end{array}$ & $\begin{array}{c}\begin{array}{c}\text { No. of intact } \\
\text { nerve }\end{array} \\
\end{array}$ & $\begin{array}{c}\text { No. of } \\
\text { recoveries }\end{array}$ & $\begin{array}{l}\text { No. of Non } \\
\text { recoveries }\end{array}$ & No. lost to follow up \\
\hline Garcia and Maeck $^{[11]}$ & 23 & 1 & 19 & 18 & 3 & 3 \\
\hline Holstein and Lewis ${ }^{[12]}$ & 7 & 2 & 5 & 3 & 0 & 4 \\
\hline Kettelkamp and Alexander ${ }^{[13]}$ & 14 & 2 & 12 & 9 & 2 & 3 \\
\hline Shaw and Sakellarides ${ }^{[14]}$ & 26 & 4 & 22 & 19 & 7 & 0 \\
\hline Packer et al. ${ }^{[15]}$ & 18 & 1 & 17 & 16 & 2 & 0 \\
\hline Mast et al. ${ }^{[16]}$ & 7 & 1 & 6 & 0 & 4 & 3 \\
\hline Shah \& Bhatti ${ }^{[17]}$ & 62 & 3 & 19 & 53 & 9 & 0 \\
\hline Bostman et al. ${ }^{[18]}$ & 75 & 6 & 43 & 60 & 15 & 0 \\
\hline Foster et al. ${ }^{[19]}$ & 14 & 7 & 7 & 9 & 4 & 1 \\
\hline Larsen et al. ${ }^{[20]}$ & 26 & 1 & 4 & 26 & 0 & 0 \\
\hline Ring et al. ${ }^{[21]}$ & 24 & 6 & 8 & 17 & 7 & 0 \\
\hline Total & 296 & $34(11.5 \%)$ & $16254.7 \%)$ & $230(77.7 \%)$ & $53(17.9 \%)$ & $13(4.8 \%)$ \\
\hline Present series & 25 & 0 & 25 & 24 & 1 & 0 \\
\hline
\end{tabular}

\section{References}

1. Shao YC, Harwood P, Grotz MR. Radial nerve palsy associated with fractures of the shaft of the humerus: a systematic review, J Bone Joint Surg. 2005; 87B:1647,

2. Alnot J, Osman N, Masmejean E, Wodecki P. Lesions of the radial nerve in fractures of the humeral diaphysis. Apropos Of 62 Cases. Rev Chir Orthop Reparatrice Appar Mot. 2000; 86(2):143-50.

3. Bodner G, Huber B, Schwabegger A, Lutz M, Waldenberger P. Sonographic detection of radial nerve entrapment within a humeral fracture. J Ultrasound Med. 1999; 18(10):703-6.

4. Amillo S, Barrios RH, Martinez-Peric R, Losada JI. Surgical Treatment of the radial nerve Lesions associated with fractures of the humerus. J Orthop Trauma. 1993; 7(3):211-5.

5. Lin J. Locked nailing of spiral humeral fractures with or without radial nerve entrapment. Clin Orthop 2002; (403):213-20.

6. Shao YC, Harwood P, Grotz MR, Limb D, Giannoudis PV. Radial nerve palsy associated with fractures of the shaft of the humerus: A systematic review. J Bone Joint Surg. 2005; 87B:1647-52.

7. Takami H, Takahashi S, Ando M. Severance of the radial nerve complicating transverse fracture of the mid- shaft of the humerus. Arch Orthop Trauma Surg. 1999; 119:109-111.

8. Bostman O, Bakalim G, Vainionpaa S, Wilppula E, Patiala H, Rokkanen P. immediate radial nerve palsy complicating fracture of the shaft of the humerus, when is early exploration justified? Injury. 1985; 16(7):4199-502.

9. Di-Filippo P, Mancini GB, Gillio A. Humeral fractures with paralysis of the radial nerve. Arch-Putti-ChirOrgani-Mov. 1990; 38(2):405- 409.

10. Vansteeenkiste FP, Rommens PM, Broos PL. Is a radial nerve paralysis in a humeral shaft fracture an indication for surgery? Indications Acta.Chir- Belg. 1989; 89(4):215-220.

11. Garcia A, Maeck Bh. Radial nerve injuries in fractures of the shaft of the humerus. Am J Surg. 1960; 99:626-627.

12. Holstein A, Lewis G. Fractures of the humerus With Radial Nerve Palsy. J Bone Joint Surg. 1963; 48A:13821388 .

13. Kettelkamp DB, Alexander H. Clinical review of radial nerve injury. J Trauma. 1967; 7:424-432.

14. Shaw JL, Sakellarides H. radial nerve paralysis associated with fractures of the humerus. A review of forty five cases. J Bone Joint Surg. 1967; 49A:899-902.

15. Packer JW, Foster RR, Garcia A, Grantham SA. The Humeral Fracture With Radial Nerve Palsy: Is Exploration Warranted? Clin Orthop. 1972; 88:34-38.

16. Mast JW, Spiegel PG, Harvey JP, Harrison C. Fractures of the humeral shaft. A retrospective study of 240adult fractures. Clin Orthop. 1975; 112:254-262.

17. Shah JJ, Bhatti NA. Radial nerve paralysis associated with fractures of the humerus: A review of 62 cases. Clin Orthop. 1983; 172:171-176.

18. Bostman O, Bakalim G, Vainionpaa S, Wilppula E, Patiala H, Rokkanen P. Radial palsy in shaft fracture of humerus. Acta-Orthop-Scand. 1986; 57(4):316-19. 
19. Foster Robert J, Swiontkowski MF, Bach AW, Sack JT. Radial nerve palsy caused by open humeral shaft fractures. J Hand Surg. 1993; 18A:121-124.

20. Larsen LB, Barfred T. Radial nerve palsy after simple fracture of the humerus. Scand J Plast Reconstr Surg Hand Surg. 2000; 34(4):363-366.

21. Ring D, Chin K, Jupiter J. Radial Nerve Palsy Associated With High Energy Humeral Shaft Fracture. J Hand Surg. 2004; 29A(1):144-7. 